\title{
Loss of heterozygosity in renal and hepatic epithelial cystic cells from ADPKD1 patients
}

\author{
Celia Badenas ${ }^{1,2}$, Roser Torra ${ }^{1}$, Laureano Pérez-Oller ${ }^{1}$, Judith Mallolas ${ }^{2}$, \\ Roberto Talbot-Wright ${ }^{3}$, Vicenç Torregrosa ${ }^{4}$ and Alejandro Darnell ${ }^{1}$ \\ ${ }^{1}$ Department of Nephrology, ${ }^{2}$ Genetics and ${ }^{3}$ Urology, ${ }^{4}$ Renal Transplant Unit, Hospital Clínic, Institut
$d^{\prime}$ Investigacions Biomèdiques August Pi i Sunyer, University of Barcelona, Spain
}

Autosomal dominant polycystic kidney disease (ADPKD) is one of the commonest genetic diseases in man, affecting 1:1000 individuals in the Caucasian population. It is caused by mutations in the PKD1 or PKD2 genes. Recently, controversial data regarding the mutational mechanism underlying cyst initiation have been reported: genetic analyses have shown that second somatic mutations may lead to cyst formation (detected as microsatellite loss of heterozygosity, LOH, and point mutations), but immunohistochemical studies show strong immunoreactivity for polycystin in some cysts. In order to further characterise this matter we have analysed 211 cysts from seven different patients for $\mathrm{LOH}$, we have detected a $13.3 \% \mathrm{LOH}$ for PKD1. This loss was specific to PKD1 as no LOH was detected when other chromosomal regions were studied. Whenever linkage analysis has been possible, it has been proved that the lost allele corresponded to the wild-type. Our data supports previous results in the two-hit theory for ADPKD due to the large number of cysts studied. ADPKD would occur through a recessive cellular mechanism. The probability of cyst development would depend on the probability of mutation in the second allele. The different phenotypical expression of the same mutation reported in ADPKD could be due to the different tendency of inactivation in the second allele in each individual. European Journal of Human Genetics (2000) 8, 487-492.

Keywords: LOH; PKD1; two-hit; cystogenesis; kidney cysts

\section{Introduction}

Autosomal dominant polycystic kidney disease (ADPKD) is one of the commonest hereditary diseases in man, affecting $1 / 1000$ individuals. It is characterised by the progressive development and enlargement of multiple fluid filled cysts in the kidney that may ultimately lead to end-stage renal disease (ESRD). ${ }^{1}$

At least three different genes are involved in this disease: polycystic kidney disease 1 (PKD1), ${ }^{2}$ localised at 16p13.3; PKD2 localised at $4 q 13-23^{3}$ and a third locus still unmapped. ${ }^{4,5}$ To date, several mutations have been described in the PKD1 and PKD2 genes, most of them are expected to produce truncated proteins (http://www.uwcm.ac.uk/uwcm/mg). These truncating mutations suggest that ADPKD is caused by inadequate levels of polycystin (ie haploinsufficiency), by a

Correspondence: Dr R Torra, Department of Nephrology, Hospital Clínic, Villarroel 170, 08036 Barcelona, Spain. E-mail: rtorra@clinic.ub.es Received 17 December 1999; revised 15 February 2000; accepted 24 February 2000 model of dominant/negative function, in which a mutated form of polycystin would inactivate the normal polycystin produced by the normal allele, or by a cellular recessive mechanism. The latter hypothesis has recently been studied due to the fact that less than $1 \%$ of nephrons become cystic. Evidence of loss of heterozygosity (LOH) at the PKD1 and PKD2 loci in cystic epithelia has been reported. ${ }^{6-12}$ suggesting that cytogenesis in ADPKD results from the inactivation of the normal copy of the gene by a second somatic mutation. On the other hand, there is also evidence that the majority of cysts show strong immunoreactivity with antibodies directed against both polycystins. ${ }^{13-16}$ The aim of this study was to search for LOH in microsatellites linked to PKD1 and PKD2 genes and the chromosome 3 marker which is frequently deleted in sometumors ${ }^{7}$ in epithelial cystic cells from ADPKD patients. We have analysed 211 renal and hepatic cysts from seven different patients for $\mathrm{LOH}$, and have detected a $13.3 \%$ LOH for PKD 1. This loss was specific to PKD 1 as no LOH was detected when other areas were studied. 


\section{Materials and methods Patients and specimens}

Seven ADPKD patients whose kidneys required surgical resection were studied. Five of them had one kidney removed due to its large size which did not leave enough room for placing a graft; patient 5 had both kidneys removed and patient 3 both kidneys and liver (this patient underwent renal and liver transplantation). All kidneys were studied immediately after the removal, which always took place in our hospital. During the entire procedure they were placed on ice in a tray. This study was approved by the Ethical Committee of the Hospital Clínic, Barcelona.

\section{Preparation of cystic epithelial cells (modified from Qian et al 1996)}

The surface of the cyst was first rinsed with PBS. After that we proceeded to drain the cyst content with a needle and a syringe. The needle was left inserted in the cyst during the washing steps. The cavity of the cyst was rinsed four to ten times with $\mathrm{Ca}^{2+}$ and $\mathrm{Mg}^{2+}$-free PBS, until the liquid looked clear. The last rinse from the cyst was collected and stored on ice. At this point PBS/2mm EDTA was introduced into the cysts and was energetically flushed in and out of the cyst several times in order to facilitate the detachment of the epithelial cells from the base membrane. Only the cysts that proved to remain intact were considered for the study. We studied a total of 211 cysts.

\section{DNA extraction}

The cells suspended in PBS/2mm EDTA were centrifuged at $14000 \mathrm{rpm}$ for $5 \mathrm{~min}$ and the supernatant was discarded. The pellet was resuspended with $600 \mu \mathrm{l}$ of urea solution (8M Urea, $0.3 \mathrm{M} \mathrm{NaCl}, 10 \mathrm{~mm}$ EDTA, 10mm TRIS, $2 \%$ SDS) and $12 \mu \mathrm{l}$ of proteinase $K$ solution $(10 \mathrm{mg} / \mathrm{ml})$. It was incubated overnight at $37^{\circ} \mathrm{C}$ and underwent a phenol/chloroform extraction. After this we added $0.5 \mu \mathrm{l}$ glycogen and $2.5 \mathrm{~V}$ absolute ethanol and incubated it for $1 \mathrm{~h}$ at $-80^{\circ} \mathrm{C}$. After the incubation we centrifuged it for $20 \mathrm{~min}$ at $14000 \mathrm{rpm}$ and discarded the supernatant. Finally, the pellet was dried and resuspended in $45 \mu \mathrm{l}$ TE.

\section{PEP PCR (Primer extension pre-amplification)}

As the washing of the cysts was very strict in order to avoid contamination, the final quantity of cells we obtained was small. This made it necessary to perform a preamplification in order to enlarge the amount of DNA for the LOH studies and the search for mutations within the PKD2 gene. The reaction included: $1-2 \mu \mathrm{l}$ DNA, $6 \mu \mathrm{l} 10 \times$ buffer, $2.5 \mathrm{~mm}$ $\mathrm{MgCl}_{2}$, DTT $4 \mathrm{~mm}, 10 \mathrm{~mm}$ of each dNTP, $400 \mu \mathrm{m}$ of each random primer (15-mer oligonucleotide in which any one of the four possible bases could be present at each position), $5 \mathrm{U}$ taq polymerase (Perkin Elmer, Foster City, California), and water to $60 \mu \mathrm{l}$. PCR amplification was performed as follows: $5 \mathrm{~min}$ at $94^{\circ} \mathrm{C}, 50$ cycles: $1 \mathrm{~min}$ at $94^{\circ} \mathrm{C}, 2 \mathrm{~min}$ at $37^{\circ} \mathrm{C}, 4 \mathrm{~min}$ at $55^{\circ} \mathrm{C}$, final extension: $7 \mathrm{~min}$ at $72^{\circ} \mathrm{C}$.

\section{Linkage and loss of heterozygosity analysis}

Linkage studies for PKD1 were performed in families from patients 1, 4, 5 and 6 . In the remaining cases only DNA from the affected patient was available.

Linkage analysis was performed using $3(\mathrm{CA})_{n}$ microsatellites for PKD1: AC2.5(D16S291)-CW2(D16S663)-PKD1KG8(3'UTR-PKD1) and $4(C A)_{n}$ microsatellites for PKD2: D4S1534-D4S1542-PKD2-D4S1563-D4S423. The technique used to study these microsatellites has previously been reported. ${ }^{17}$ All four families were found to be linked to the PKD1 locus. In one of them (patient 6) the causative mutation had been previously determined (12801del28). ${ }^{18}$

For LOH studies the microsatellites studied were: D16S663 (CW2), D16S291 (AC2.5), KG8-3'UTR, D4S1563 and D3S1478. One $\mu$ l of DNA or $2 \mu l$ of PEP-PCR were used for each PCR reaction. We used $7 \%$ DMSO and $1.5 \mathrm{~mm}$ (KG8-3'UTR, CW2, D4S1563 and D3S1478) or $1 \mathrm{~mm}$ (AC2.5) $\mathrm{MgCl}_{2}$. The PCR conditions were as previously described. ${ }^{17}$ The PCR products were run on a $5 \%$ denaturing polyacrylamide gel and silver stained. ${ }^{19} \mathrm{LOH}$ was determined by visual comparison of signals obtained from amplification of cysts and control DNA. All PCR reactions showing LOH were repeated 3 times for confirmation.

Patient 6 belonged to a previously studied family in which the mutation had been detected using primers JJ: 12801del28. To study this patient PCR amplifying this fragment was used, following previously described conditions. ${ }^{18}$ For LOH studies PCR products were electrophoresed in a $12 \%$ non-denaturing polyacrylamide gel and silver stained.

\section{Search for mutations in the PKD2 gene}

The primers used for exon amplification and PCR conditions have been previously described. ${ }^{20}$ We performed SSCP analysis of the entire coding region for patients 2,3 , and 7 , in which linkage analysis was not possible. We studied exons $1 C, 4,5,6,7,8,9,11$ and 14 with kidney from patient 4 . We selected this patient because he had one of the highest LOH percentages for PKD 1.

SSCP analysis was performed with three $\mu$ of PCR product being combined with loading buffer, denatured and electrophoresed in a $12 \%$ non-denaturing acrylamide for $1^{\frac{3}{4}}$ to $2 \mathrm{~h}$ at $15^{\circ} \mathrm{C}$ or $3 \mathrm{~h}$ at $5^{\circ} \mathrm{C}$ (for exon 4,5 and 8 ) using the genephor (Pharmacia Biotech, Uppsala, Sweden) following the manufacturer's instructions. The various migrations were silverstained.

\section{Results}

\section{Linkage analysis}

Linkage analysis was performed in patients 1, 4, 5 and 6, where blood samples from patients and relatives were available. In all of them a positive linkage for PKD1 and negative for PKD2 was detected. In the remaining cases (patients2, 3 and 7) blood samples were only available from 
the patients, so linkage analysis was not performed. These patients showed clinical features compatible with ADPKD type 1. Moreover, we searched for mutations in the entire PKD2 coding region and we did not detect any mutation (mutation detection by SSCP/heteroduplex analysis for PKD2 in our studies is $87.5 \%)^{21,22}$

\section{Chromosome16p13 LOH}

All the patients studied were informative for at least two of the three microsatell ites studied. In the case of patient 6 only the fragment containing the deletion (with primers JJ) was used. Chromosome16p13 LOH was detected in 28/211 PKD 1 cysts (Table1). The size of the deletion could not be defined in any cyst, due to the fact that all cysts with LOH had lost all

Table $1 \mathrm{LOH}$ in the PKD1 gene in 211 cysts from seven patients with autosomal dominant PKD1

\begin{tabular}{|c|c|c|c|c|c|}
\hline Patient & & $\begin{array}{l}\text { No. of cysts } \\
\text { with } \mathrm{LOH}\end{array}$ & $\begin{array}{l}\text { No. of cysts } \\
\text { studied }\end{array}$ & $\% \mathrm{LOH}$ & Linkage \\
\hline 1 & Kidney & 3 & 28 & 10.7 & PKD1 \\
\hline 2 & Kidney & 3 & 28 & 10.7 & not available \\
\hline \multirow[t]{3}{*}{3} & Kidney 1 & 4 & 28 & 14.3 & not available \\
\hline & Kidney 2 & 2 & 15 & 13.3 & \\
\hline & Liver & 3 & 15 & 20 & \\
\hline 4 & Kidney & 4 & 21 & 19 & PKD1 \\
\hline \multirow[t]{2}{*}{5} & Kidney 1 & 4 & 28 & 14.3 & PKD1 \\
\hline & Kidney 2 & 1 & 13 & 7.7 & \\
\hline 6 & Kidney & 2 & 30 & 6.7 & $\mathrm{PKDI}^{\mathrm{a}}$ \\
\hline 7 & Kidney & 2 & 15 & 13.3 & not available \\
\hline Total & & 28 & 211 & 13.3 & \\
\hline
\end{tabular}

an patient 6 mutation had been previously described: 12801del28. the microsatellite studied in the PKD1 region. The allele which was lost was always the same for all cysts, which strongly suggested that it was the wild type allele in the cases where linkage analysis had not been possible (Figure 1). In patients 1, 4 and 5 linkage analysis was informative and in all cysts from these patients the allele that was lost was the wild type. In the case of patient 6, as the causative mutation had been detected ${ }^{18}$ mutational analysis was used to look for LOH directly. In the two cysts in which LOH was observed, it was the wild-type allele that was lost (Figure2).

\section{LOH specific to the PKD1 locus: chromosome4q13-23, chromosome3p microsatellite analysis, SSCP analysis} In order to check whether the LOH was specific to PKD 1 in PKD1 patients, or if it was just a consequence of the state of proliferation of the epithelial cells, we studied other chromosomal regions: i) PKD2, since it had been suggested that somatic changes at other loci which may encode proteins that interact with polycystin could play a role in cyst development; ${ }^{6}$ and ii) chromosome $3 p$, which is not suspected to play a role in cyst development but is frequently lost in other human tumours, and in which Brasier and Henske $^{7}$ detected LOH in one of the cysts studied.

For PKD 2 westudied microsatellite D4S1563 for all patients and performed SSCP analysis on exons 1 C, 4, 5, 6, 7, 8, 9, 11 and 14 in patient 4 . We selected this patient because he had one of the highest LOH percentages for PKD1. D4S1563 was informative for all patients except patient 5 . For chromosome3p we studied D3S1478 which was informative for all patients studied. We did not detect any LOH in any of these microsatellite, and no abnormal pattern on SSCP analysis on

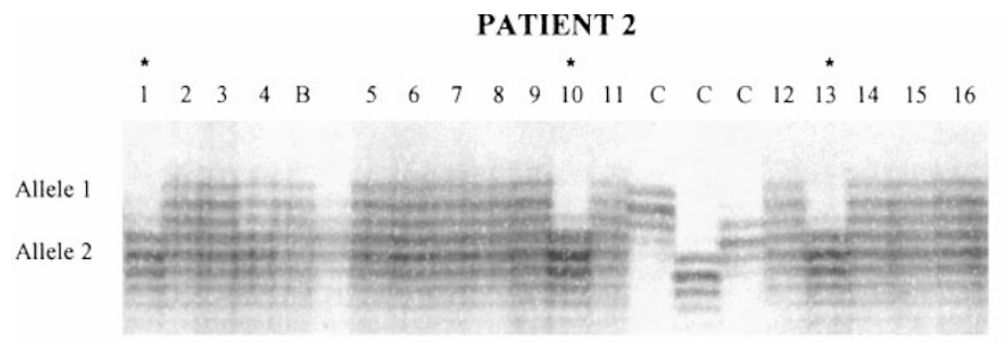

CW2

\section{PATIENT 3}

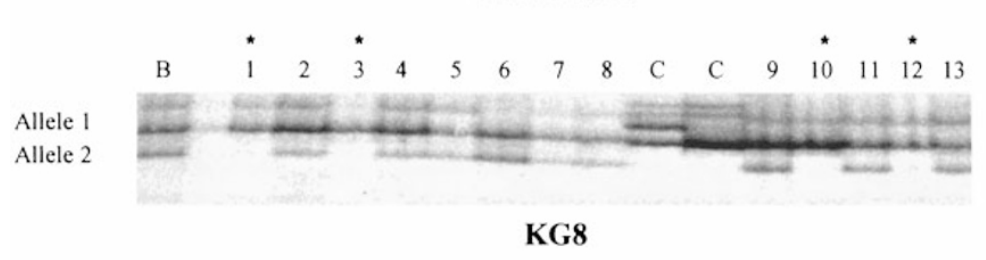

PATIENT 4
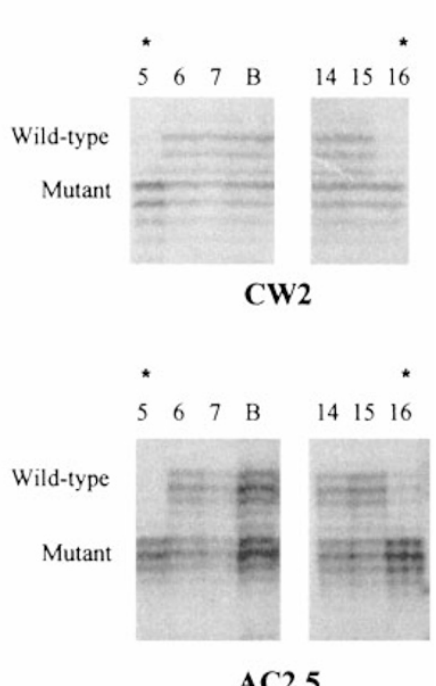

Figure 1 Analysis of microsatellite markers on chromosome $16 \mathrm{p} 13.3$ in different cysts from three PKD1 patients. C: control DNA, B: control DNA from the blood of patients, Numbers indicate different cysts. Asterisks indicate cysts in which LOH has been detected. KG8 marker in patient 3 show one larger band; this band is due to inespecificities from the PEP-PCR. 


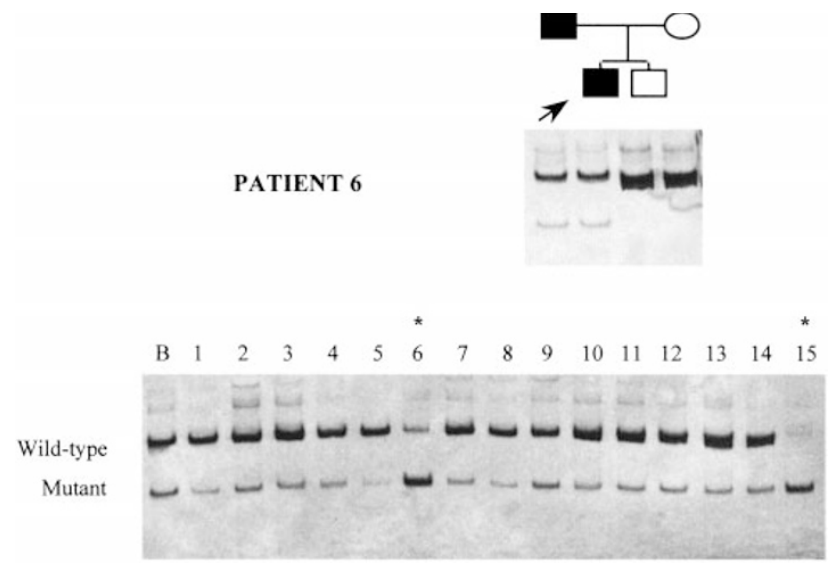

Figure 2 Loss of heterozygosity (LOH) for JJ in cysts from kidney patient 6 . Top: family study in which 12801 del28 is detected in patient 6 (indicated by an arrow) and his affected father. Bottom: LOH study in 15 cysts from patient 6 . The majority of cysts have the same pattern as the blood, but two of them (C6 and C15) demonstrate LOH. In C15 the wild-type allele is no longer seen, while in $\mathrm{C} 6 \mathrm{LOH}$ seems partial as the wild-type allele is still present. We think that there is $\mathrm{LOH}$ in this cyst but there is non-cystic cell contamination. B: control DNA from the blood of patients. Numbers indicate different cysts. Asterisks indicate cysts in which $\mathrm{LOH}$ has been detected.

the PKD2 sequencestudied was detected when studying cysts from patient 4 .

\section{Discussion}

ADPKD shows a significant interfamilial and intrafamilial variability based not only in the severity of renal disease but also in extrarenal development. ${ }^{18,23,24}$ The interfamilial variability may be partially explained by the genetic heterogeneity of this disease, with at least three genes accounting for it, but intrafamilial variability is less easy to explain. This variability is not only evident in the clinical features of the patients but also in the kidneys. Less than $1 \%$ of all nephrons from one polycystic kidney will become cystic. It is difficult to understand why only some of them develop cysts when all the epithelial cells have the same germline mutation.

It has been demonstrated previously that epithelial cells isolated from individual cysts are monoclonal and a model of cystogenesis that fits Knudson's two-hit tumour suppressor gene model has been proposed. ${ }^{6,7}$ The loss of the wild type allele would constitute a second hit which would be necessary for disease expression. Thus, a germline and a somatic inactivation of both copies of a PKD gene confers growth advantages for an individual cell to expand clonally into a cyst. It has been proved that a percentage of cells from different cysts show LOH or inactivating mutations in PKD 1 or PKD2 (Table2) both in renal and hepatic cystic epithelia in PKD1 or PKD2 patients, respectively. Renal epithelial cells have been demonstrated to be a frequent target tissue for somatic mutation. Martin et $\mathrm{al}^{25}$ demonstrated that somatic mutation in these cells is a frequent event. There are several reasons why renal epithelial cells are so prone to suffer from somatic mutations: they are metabolically active and consume large amounts of oxygen, they perform the majority of the secretory and resorptive work to obtain the renal filtrate, they are mitotically competent, specially when an injury to the kidney has occurred and eventually they are the cells from which the primary renal tumor and adenocarcinoma arise. It remains to be answered if other extrarenal features of ADPKD, such as intracranial aneurysms, also arise from a second-hit mechanism. This hypothesis is quite feasible as all extrarenal features of ADPKD are focal and may arise from a single cell.

Although much evidence supports the LOH theory, this approach to cystogenesis has been challenged. Several studies

Table 2 Reported LOH for the PKD1 and PKD2 loci

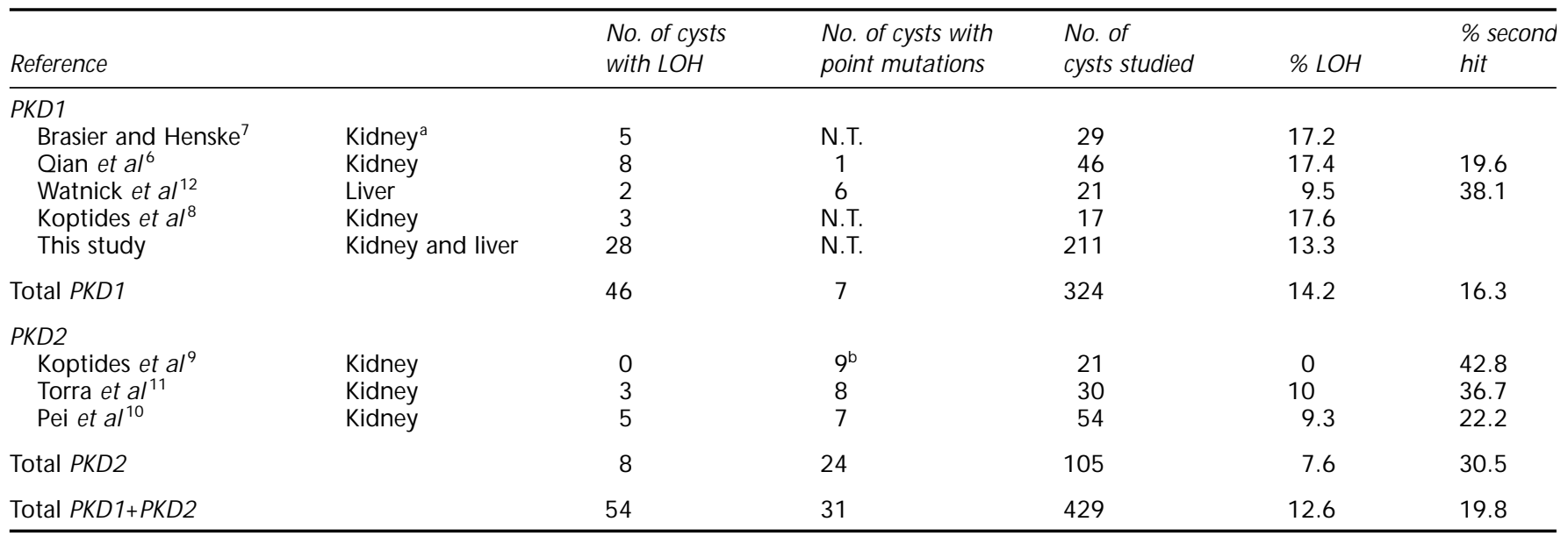

N.T. Not tested; ain one cyst without LOH in 16p, LOH was detected in 3p; bin seven cysts the same mutation was detected; \% second hit: represents percentage of cysts with known LOH or PKD mutation. 
have shown strong immunoreactivity for both polycystins in the vast majority of cyst epithelia. It is difficult to reconcile this finding with the fact that both PKD1 or PKD2 alleles may be lost in some cysts and thus no protein is expected to be present in those cysts. The possible reconciliation between both findings may be based on the fact that about $20-30 \%$ of cysts do not express polycystin, ${ }^{26}$ in the remaining cysts the somatic mutation might not disrupt the mRNA reading frame or could be a missense mutation. But from the results obtained in PKD1 and PKD2 where the second hits detected are mostly LOH or truncating mutations, ${ }^{9-12}$ no expression of polycystin should be observed. Other explanations for this apparent contradiction could be that inactivating mutations prolong the half-life of polycystin, or the absence of polycystin could induce the loss of feed-back for the synthesis of an abnormal protein. ${ }^{7}$

We have studied nine kidneys and one liver of PKD1 patients and detected a rate of $\mathrm{LOH}$ of $13.3 \%$. This represents the largest number of cysts studied to date. This prevalence of LOH is a little lower than in other PKD 1 studies, but higher than in PKD2 (Table2). The difference with other PKD1 studies could be due to the large number of cysts analysed in this study (211), higher than in any other, and to the different percentage of LOH detected between kidneys (our range is $6.7-20 \%$ ). Moreover, we have only included in this study those cysts in which presence or absence of LOH could be proved three times, those with unclear results were not included (LOH was detected in some cysts, but when repeated it was not present); this may be the reason for underestimation of $\mathrm{LOH}$ in the percentage given in this study. LOH is higher in PKD1 than in PKD2 cysts, this could be the result of a different mutational mechanism, gross deletions being more frequent in PKD 1 than in PKD2. PKD2 mutational screening in cysts has been performed and a great percentage of cysts showing somatic point mutations has been detected..$^{9-11}$ If we take into account both mutational mechanisms, we can see that there is no wild-type PKD2 protein in at least $30 \%$ of PKD2 cysts. As these studies did not screen all the PKD2 coding sequence, it is feasible that the percentage of point mutations is greater than detected. On the other hand, PKD 1 mutational screening is very difficult: it is a very large gene, with all but $3.5 \mathrm{~kb}$ reiterated more proximally on the same chromosome and a small number of mutations being found in more than one family. Up to now, only 60 mutations have been identified, most of them resulting in a truncated protein (http://www.uwcm.ac.uk/ uwcm/mg). Only in one PKD1 kidney mutational screening has been performed in cysts. ${ }^{12}$ The authors searched for microsatellite $\mathrm{LOH}$ and a $9.5 \%$ rate was detected. They also screened from exon 15 to 34 of PKD1 and detected six different point mutations (representing 28.6\%). Thus, the average of second hit mutations is at least $38 \%$ (Table2). There are several reasons why not every cyst shows LOH: point mutations could account for the second step, and although we performed a strict washing of the cyst cavity, we cannot exclude contamination from cells other than the cyst epithelial cells and thus a false negative result would appear.

There is a possibility that the loss of one allele is the consequence of the process of hyperplasia which a cell undergoes and the consequent state of dedifferentiation that cells arising from this first cell achieve. In order to prove whether LOH was specific for ADPKD genes, we tested one microsatellite from a region frequently deleted in some tumours, but did not find LOH for this marker in the cysts studied. Moreover, no PKD1 cysts lost any PKD2 allele. Brasier and $\mathrm{Henske}^{7}$ al so studied PKD 2 markers in PKD 1 cysts and did not observe LOH. These findings support the theory that LOH constitutes an initial process during cyst formation.

Our data supports the implication of a molecular recessive mechanism in the process of cystogenesis for ADPKD1. Polycystin may be implicated in regulation of renal epithelial cell growth ${ }^{27}$ and the loss of both copies of the ADPKD gene causes hyperplasia of a given cell resulting in a cyst. This fact has important implications, because if we assume that the lack of normal polycystin is implicated in cyst formation, treatment strategies directed towards reducing the rate of second hits or the administration of polycystin to the kidneys could prevent or slow the progressive formation and enlargement of cysts.

\section{Acknowledgements}

This work was supported by a grant of the Fondo de Investigaciones Sanitarias de la Seguridad Social (FIS97/2047) and La Marató-TV3 $(98 / 210)$. CB is a recipient of a fellowship from the Instituto de Salud Carlos III (ref. 98/4012). LPO is a recipient of a fellowship from the Generalitat de Catalunya (99/691). This study would not have been possible without the generous co-operation of the patients and their families.

\section{References}

1 Gabow PA: Polycystic kidney disease: clues to pathogenesis. Kidney Int 1991; 40: 989-996.

2 European Polycystic Kidney Disease Consortium: The polycystic kidney disease 1 gene encodes a $14 \mathrm{~Kb}$ transcript and lies within a duplicated region on chromosome16. Cell 1994; 77: 281-314.

3 Mochizuki T, Wu G, Hayashi T et al: PKD2, a gene for polycystic kidney disease that encodes an integral membrane protein. Science 1996; 272: 1339-1342.

4 Daoust MC, Reynolds DM, Bichet DG, Somlo S: Evidence for a third genetic locus for autosomal dominant polycystic kidney disease. Genomics 1995; 25: 733-736.

5 De Almeida S, De Almeida E, Peters $D$ et al: Autosomal dominant polycystic kidney disease: evidence for the existence of a third locus in a Portuguese family. Hum Genet 1995; 96: 83-88.

6 Qian F, Watnick TJ, Onuchic LF, Germino GG: The molecular basis of focal cyst formation in human autosomal dominant polycystic kidney disease type1. Cell 1996; 87: 979-987.

7 Brasier JL, Henske EP: Loss of the polycystic kidney disease (PKD1) region of chromosome16p13 in renal cyst cells supports a lossof-function model for cyst pathogenesis. J Clin Invest 1997; 99: 194-199. 
8 Koptides M, Constantinides R, Kyriakides $G$ et al: Loss of heterozygosity in polycystic kidney disease with a missense mutation in the repeated region of PKD1. Hum Genet 1998; 103: 709-717.

9 Koptides M, Hadjimichael C, Koupepidou P, Pierides A, Constantinou-Deltas C: Germinal and somatic mutations in the PKD2 gene of renal cysts in autosomal dominant polycystic kidney disease. Hum Mol Genet 1999; 8: 509-513.

10 Pei $Y$, Watnick T, HeN et al: Somatic PKD2 mutations in individual kidney and liver cysts support a 'two-hit' model of cystogenesis in type 2 autosomal dominant polycystic kidney disease. J Am Soc Nephrol 1999; 10: 1524-1529.

11 Torra A, Badenas C, San Millán JL, Pérez-Oller L, Estivill X, Darnell $A$ : A loss-of-function model for cystogenesis in human autosomal dominant polycystic kidney disease type2. Am J Hum Genet 1999; 65: 345-352.

12 Watnick TJ, Torres VE, Gandolph MA et al: Somatic mutation in individual liver cysts supports a two-hit model of cytogenesis in autosomal dominant polycystic kidney disease. Molecular Cell 1998; 2: 247-251.

13 Geng L, Segal Y, Peissel B et al: Identification and localization of polycystin, the PKD1 gene product. J Clin Invest 1996; 98: 2674-2682.

14 Ward CJ, Turley H, Ong AC et al: Polycystin, the polycystic kidney disease 1 protein, is expressed by epithelial cells in fetal, adult, and polycystic kidney. Proc Natl Acad Sci USA 1996; 93: 1524-1528.

15 Ibraghimov-Beskrovnaya O, Dackowski WR, Foggensteiner L, Coleman N, Thiru S, Petry LR: Polycystin: In vitro synthesis, in vivo tissue expression, and subcellular localization identifies a large membrane-associated protein. Proc Natl Acad Sci USA 1997; 94: 6397-6402.

16 Ong ACM, Ward CJ, Butler RJ et al: Coordinate expression of the autosomal dominant polycystic kidney disease proteins, polycystin-2 and polycystin-1, in normal and cystic tissue. Am J Pathol 1999; 154: 1721-1729.
17 Torra R, Badenas C, Darnell et al: Linkage, clinical features and prognosis of ADPKD types 1 and 2. J Am Soc Neph 1996; 7: 2142-2151.

18 Torra R, Badenas C, Darnell A, Bru C, Escorsell A, Estivill X: Autosomal dominant polycystic kidney disease with anticipation and Caroli's disease associated with a PKD 1 mutation. Kidney Int 1997; 52: 33-38.

19 Bassam BJ, Caetano-Anolles G, Gresshoff PM: Fast and sensitive silver staining of DNA in polyacrylamide gels. Anal Biochem 1991; 196: 80-83.

20 Hayashi T, Mochizuki T, Reynolds DM, Wu GQ, Cai Y, Somlo S: Characterization of the exon structure of the polycystic kidney disease 2 gene (PKD2). Genomics 1997; 44: 131-136.

21 Torra R, Viribay M, Tellería D et al: Seven novel mutations of the PKD2 gene in families with autosomal dominant polycystic kidney disease. Kidney Int 1999; 56: 28-33.

22 Viribay M, Hayashi T, Tellería D et al: Novel stop and frameshifting mutations in the autosomal dominant polycystic kidney disease2 (PKD2) gene. Hum Genet 1997; 101: 229-234.

23 Peral B, Ong AC, Sam Millán JL, Gamble V, Rees L, Harris PC: A stable nonsense mutation associated with a case of infantile onset polycystic kidney disease1 (PKD1). Hum Mol Genet 1996; 5: 539-542.

24 Hateboer N, Van Dijk MA, Bogdanova N et al: Comparison of phenotypes of polycystic kidney disease types 1 and 2. European PKD1-PKD2 Study Group. Lancet 1999; 353: 103-107.

25 Martin GM, Ogburn CE, Colgin LM, Gown AM, Edland SD, Monnat RJ: Somatic mutations are frequent and increase with age in human kidney epithelial cells. Hum Mol Genet 1996; 5: 215-221.

26 Torres VE: New insights into polycystic kidney disease and its treatment. Curr Opin Nephrol Hypertens 1998; 7: 159-169.

27 Van Adelsberg J: Peptides from the PKD repeats of polycystin, the PKD 1 gene product, modulate pattern formation in the developing kidney. Dev Genet 1999; 24: 299-308. 